\title{
UMA ANÁLISE DO ENSINO SOBRE ANFÍBIOS NA EDUCAÇÃO BÁSICA
}

\author{
Marina Petzen Vieira dos Santos* \\ Elaine Maria Lucas** \\ Fábio Luiz Carasek ${ }^{* * *}$
}

Resumo: No ensino de Biologia, os conteúdos são bastante diversos e relacionados ao cotidiano dos estudantes, possibilitando a relação entre a teoria e a prática. O conteúdo sobre os anfíbios apresenta grande potencial para ser trabalhado de maneira dinâmica e alternativa no ambiente escolar, pois muitos aspectos interessantes sobre o grupo podem ser abordados. Neste contexto, este estudo teve como objetivo conhecer como a temática anfíbios é trabalhada no ensino médio. A pesquisa foi realizada no ano de 2007, de maneira qualitativa em $20 \%$ das escolas estaduais do município de Chapecó, estado de Santa Catarina, sendo entrevistados dez professores da disciplina de Biologia atuantes no ensino médio destas escolas.

Palavras-chave: Biologia. Ensino médio. Métodos de ensino. Anfíbios. 
Abstract: In the teaching of biology, the contents are quite different and related to the daily lives of students, enabling the relationship between theory and practice. The content about amphibians has great potential to be teached in a dynamic and alternative way in school space, then many interesting aspects about the group can be addressed. In this context, this study aimed to understand how the amphibian theme is teached in high school. The survey was conducted in 2007, in a qualitative way in $20 \%$ of state schools in the Chapecó, state of Santa Catarina, being interviewed ten biology teachers that are acting in high school.

Keywords: Biology. High School. Teaching methods. Amphibians. 


\section{Introdução}

A Biologia é uma ciência com elevada riqueza de conteúdos, sendo facilmente estabelecida a relação entre a teoria e a prática. No entanto, devido a esta ampla diversidade temática, os conteúdos geralmente precisam ser abordados de maneira reduzida pelos educadores nas escolas, mas devem proporcionar aos estudantes conhecimentos necessários a uma visão ampla e crítica, além de instigá-los na busca de novos conhecimentos (KRASILCHIK, 2005). Para Weissmann (1998), por ser esta uma disciplina que requer visão de espaço, de cotidiano e de envolvimento com o interesse dos estudantes, o educador deve abordar os conteúdos por meio de aulas que despertem o interesse dos mesmos.

O aprendizado é proposto de forma a propiciar aos estudantes o desenvolvimento de uma compreensão do mundo que lhes dê condições de continuamente colher e processar informações, desenvolver sua comunicação, avaliar situações, tomar decisões, ter atuação positiva e crítica em seu meio social (LIBÂNEO, 2004). É de responsabilidade da escola e do professor promover o debate e a investigação, visando o entendimento da Ciência como construção histórica e saber prático, superando as limitações do ensino caracterizado pela memorização (BRASIL, 2000).

Até pouco tempo, muitos conteúdos relacionadas a disciplina de Biologia eram abordados com simples memorização, mas diversos deles, como os relacionados ao estudo dos seres vivos, deveriam ter enfoque mais significativo (COSTA; COSTA, 2006). Nos livros didáticos, por exemplo, normalmente não é encontrada uma abordagem que relacione as questões ambientais e os problemas decorrentes da diminuição brusca ou extinção de determinadas 
espécies (KINDEL et al., 1997), fundamental para a compreensão das inter-relações entre os seres vivos e seus ambientes. Neste contexto, ao estudar os seres vivos, é desejável desenvolver atividades acerca das espécies e situações ambientais encontradas regionalmente, proporcionando aos estudantes a relação do conteúdo com o cotidiano. Assuntos ligados às crescentes ameaças antrópicas à biodiversidade precisam ser abordados nas escolas, sendo esta uma importante oportunidade de fornecer subsídios à implementação de projetos de educação e conservação ambiental, possibilitando demonstrações de respeito e conservação à natureza (FONSECA, 2007).

Os anfíbios são animais importantes nas cadeias e teias ecológicas, pois são controladores de insetos e outros invertebrados, e servem de alimento para muitas espécies de vertebrados, como répteis, aves, mamíferos e até mesmo outros anfíbios (DUELLMAN; TRUEB, 1994). Estudos recentes apontam para a grande sensibilidade dos anfíbios em relação às alterações ambientais impostas pelo homem, e por isso é um grupo que vêm sendo utilizado como indicador de qualidade dos ambientes (SEYMOUR et al., 2001). Diversas espécies mais tolerantes podem ser observadas se reproduzindo em ambientes bastante próximos aos centros urbanos. Os anfíbios também são alvo de diversos estudos para a produção de fármacos a partir dos compostos ativos presentes na pele destes animais (SEBBEN et al., 1993). No entanto, na cultura popular, é comum surgirem estórias equivocadas sobre os anfíbios, principalmente os sapos, as quais podem contribuir para a matança indiscriminada destes animais (KINDEL et al., 1997). Estas questões representam oportunidades interessantes para discussões acerca da conservação biológica e desenvolvimento de 
atividades diferenciadas sobre esta temática no ambiente escolar, e podem contribuir para despertar maior interesse dos estudantes.

O objetivo deste estudo foi conhecer como a temática anfíbios vem sendo trabalhada no ensino médio de escolas públicas do município de Chapecó, estado de Santa Catarina, abordando principalmente aspectos acerca da percepção, métodos de ensino e dificuldades dos professores no ensino dos anfíbios.

\section{Procedimentos metodológicos}

\section{1. Área de estudo}

O universo da pesquisa compreendeu seis escolas, representando $20 \%$ das escolas públicas estaduais do município de Chapecó, estado de Santa Catarina ( $27^{\circ} 05^{\prime} 47^{\prime \prime}$; ; 52 37’ 6”O). As escolas foram selecionadas considerando o maior número de estudantes matriculados no ensino médio do município, de acordo com informações fornecidas pela Gerência de Educação do município no ano de estudo.

\section{Coleta de dados}

As entrevistas foram realizadas durante o mês de setembro de 2007, onde foram entrevistados dez professores, representando $100 \%$ dos professores da disciplina de Biologia atuantes na $2^{\text {a }}$ série do ensino médio das escolas alvo deste estudo. 
Caracteriza-se por uma pesquisa qualitativa, em que os professores foram entrevistados, após autorização, a partir de entrevista semiestruturada e gravador cassete, quando possível. As entrevistas continham 14 questões abertas, que quando gravadas foram transcritas e os dados organizados e analisados a partir da similaridade das respostas.

\section{Resultados e discussões}

Perfil dos professores entrevistados

Os professores entrevistados são graduados em Ciências Biológicas, e concluíram suas graduações no período de 1970 a 2000. Cinquenta por cento dos professores ministram aulas de Biologia a um período inferior a dez anos, 20\% lecionam entre 16 e 20 anos e os 30\% restantes atuam entre 11 e 15 anos. Todos os professores entrevistados possuem pós-graduação em nível lato sensu.

Aprendizado, percepção e dificuldades no ensino dos anfíbios

A maioria dos professores entrevistados (70\%) não teve aula prática de anfíbios em sua graduação. Segundo os depoimentos, as aulas tratavam basicamente de aspectos morfológicos e nomenclaturais, não sendo abordados temas relacionados a diversidade e conservação.

Os professores que tiveram aula prática de anfíbios em sua graduação (30\%) foram os que se formaram há mais tempo (1970, 
1978 e 1986). É importante considerar que, recentemente, o processo de formação de professores tornou-se mais rápido; em consequência disso, a carga horária curricular foi diminuída e os formadores precisaram suprimir muitas atividades relevantes no processo formativo (BRUSCHI, 2002). Dentre os que tiveram aulas práticas, um deles, formado em 1970, citou que não havia problemas ambientais e por isso não estudou aspectos relacionados a ecologia. Sobretudo, outro professor, formado em 1978, enfatiza que eram abordados temas relacionados a preservação, ecologia e queimadas. Neste sentido, pode-se notar que, em um tempo relativamente curto, as preocupações ambientais podem ter se intensificado.

Quando questionados sobre sua percepção em relação aos anfíbios, metade dos professores (50\%) lembrou da importância do grupo na cadeia alimentar, incluindo uma resposta relacionada a sua utilização para alimentação humana, seguida da importância ecológica (20\%) e utilização do grupo como bioindicadores (20\%). A importância do grupo em relação a interações ecológicas ou mesmo como bioindicadores foi pouco lembrado, enquanto que o valor de existência e a utilização dos compostos ativos presentes na pele dos anfíbios na indústria farmacológica não foram lembrados. Três professores não responderam a questão de maneira objetiva, respondendo apenas que são importantes.

Durante as entrevistas, foram discutidos aspectos relacionados aos anfíbios e o meio ambiente, a conservação da diversidade de espécies, os problemas ambientais, entre outros. Setenta por cento dos professores relataram que os livros didáticos não abordam estes temas, fazendo com que eles busquem materiais alternativos para trabalhar as questões ambientais em sala de aula, enquanto os demais professores entrevistados salientaram que estes assuntos são enfatizados nos livros didáticos adotados, e que facilitam 
o desenvolvimento da aula. A escolha dos livros didáticos é realizada no início dos anos letivos pelos professores; então, para que os livros que serão utilizados na escola tenham boa qualidade, é imprescindível que os professores façam uma avaliação dos conteúdos e abordagens estabelecidas nas obras sugeridas pelo Ministério da Educação (MEC). Nas escolas pesquisadas, todos os livros são disponibilizados pelo MEC.

Cinquenta por cento dos professores relataram que ao ensinar sobre anfíbios priorizam a desmitificação das diversas crendices relacionadas ao grupo, bem como a importância ecológica destes no ambiente, enquanto $20 \%$ relacionaram a importância do estudo dos anfíbios ao cumprimento do programa de ensino. Outras respostas, menos frequentes, estiveram relacionadas com a importância no grupo em relação a cadeia alimentar, biodiversidade e interação com o homem. Um dos professores comentou que muitas vezes não trabalha a temática por falta de tempo. Segundo Vasconcellos (2004), os programas de ensino são vistos pelos professores como verdadeiros dogmas que devem ser cumpridos sem que a validade ou importância destes seja questionada. Vasconcellos (2004) considera que, de maneira geral, nas escolas, a maior preocupação dos professores é "cumprir o cronograma", pois acreditam que este foi elaborado por pessoas competentes, bem-intencionadas e que é a melhor maneira de ensinar seus alunos. Sobretudo, percebe-se que, por precisarem ou acreditarem que precisam cumprir o cronograma, muitas vezes, os professores não trabalham ou não dão a devida relevância a alguns temas pertinentes (VASCONCELLOS, 2004).

A totalidade dos professores entrevistados gosta de trabalhar a temática anfíbios com o ensino médio, pois entende que o as- 
sunto é atrativo aos estudantes, talvez por serem animais presentes no cotidiano da maioria deles. Apesar disso, para 40\% dos professores, a principal dificuldade percebida no ensino, de uma forma mais geral, está relacionada ao desinteresse dos estudantes, sendo que dificilmente participam ou fazem questionamentos. A Biologia pode ser uma das disciplinas mais relevantes e merecedoras da atenção dos estudantes, ou uma das mais insignificantes e pouco atraentes, dependendo do que é ensinado e como é ensinado (KRASILCHIK, 2005). O sucesso do educador é avaliado em termos de seu sucesso com os estudantes; então, se o estudante não está aprendendo, o educador precisa mudar o que está fazendo, ou seja, se não houve aprendizagem autêntica, o educador tem que mudar de estratégia (BRUSCHI, 2002). Para os demais professores entrevistados, a falta de livros, laboratórios, materiais que tratem de temas atuais e curiosidades, estagiário para o laboratório e a falta de conhecimento para elaboração de aulas práticas são fatores que dificultam e até impossibilitam a realização de algumas atividades para o ensino da temática, essencialmente em relação às atividades práticas.

Poucos professores (20\%) relataram não encontrar dificuldades para o ensino sobre os anfíbios. Estes professores ministram exclusivamente aulas teóricas, e demonstraram uma tendência de utilizar o livro didático durante a entrevista e alguns equívocos sobre o conteúdo.

Os professores relataram que encontram dificuldades para responder os questionamentos dos estudantes sobre reportagens divulgadas na mídia. Segundo a percepção dos professores, os estudantes possuem algumas aversões aos anfíbios, mas geralmente simpatizam com estes após as aulas. Santin e Cominetti (2006) e Gazoni 
e Werlang (2004) identificaram que algumas aversões estão relacionadas a urina e veneno dos sapos. De acordo com Kindel et al. (1997), as estórias relacionadas aos animais podem estar associadas ao sentimento de nojo, medo e aversão que as pessoas empregam a estes animais, os quais são considerados feios e repulsivos. Gazoni e Werlang (2004) sugerem cautela ao professor ao trabalhar assuntos que envolvem estórias, pois é muito importante que o encanto presente no imaginário dos alunos não se perca. $\mathrm{O}$ ensino não deve anular ou desrespeitar o universo cultural do aluno, pelo contrário, deve trazer a ele explicações que a Ciência tem para tais seres e/ou fenômenos (SONCINI; CASTILHO JR., 1991).

\section{Métodos de ensino}

A totalidade dos professores entrevistados trabalha o tema de maneira expositiva e foi possível identificar que poucos professores desenvolvem atividades com o auxílio de textos complementares ao livro didático, aulas práticas e/ou saídas a campo. Durante a entrevista um professor relatou:

Eu sou uma professora conteudista, querendo ou não me preocupo com o mínimo que eles tenham que ver nos três anos, então muitas vezes podíamos ter ido ao laboratório e acaba passando. Quando a turma é muito tumultuada a gente sabe que pra levar eles no laboratório a aula não rende o que renderia, muitas vezes tem turma que não vai porque poderá não ter a produção que a gente espera. (Professor A).

No entanto, as aulas práticas ou demonstrativas em Biologia são importantes e servem justamente em casos nos quais o profes- 
sor deseja economizar tempo, ou não dispõe de materiais suficientes para toda a turma, proporcionando também a visualização de determinado material de maneira simultânea por todos os alunos (KRASILCHIK, 2005).

O método de aulas expositivas, bem como o ensino centrado no professor, pode ser modificado a partir da introdução de discussões nas aulas, chamadas de exposições dialogadas (KRASILCHIK, 1996). As perguntas que intercalam as exposições dos professores motivam os alunos, servem para controlar a turma, ganhar a atenção e auxiliam no raciocínio, ao invés de limitá-los a ouvir apenas o professor (KRASILCHIK, 2005). Para Krasilchik (1996), a transição da aula em que só o professor fala para a aula dialogada, na qual o aluno participa ativamente, é um sensível progresso nas aulas de Biologia, porém muitos professores não incluem as atividades dialogadas em suas aulas principalmente por falta de segurança.

Apesar de teoricamente as aulas essencialmente expositivas serem rejeitadas, no cotidiano das escolas percebe-se que estas representam o método de ensino mais utilizado, talvez pelo fato dos educadores ainda não terem encontrado formas de realizar atividades práticas diferenciadas e também porque geralmente é mais fácil trabalhar com aulas expositivas e de maneira tradicional (VASCONCELLOS, 2004).

Admite-se que todo aluno já possui um acervo de conhecimento e muitas palavras diferentes são usadas para identificar esse acervo: ideias, crenças, significados, concepções, estruturas qualificadas como erradas, ingênuas, espontâneas e infantis. Estas expressões, com freqüência, implicam que os alunos já trazem para a sala de aula ideias próprias, mas inadequadas, que influenciam 
fundamentalmente e criam dificuldades não apenas no aprendizado do conteúdo, mas também no de habilidades como a da observação, tão essencial na Biologia (KRASILCHIK, 1996).

Gazoni e Werlang (2004) perceberam que, ao invés de trabalhar com explicações longas, cansativas e com o uso de palavras ausentes no cotidiano dos alunos, é preferível partir do conhecimento que eles possuem e procurar saber se ocorrem mitos e lendas em torno dos animais, por exemplo, para trabalhar a desmitificação em sala de aula. Para Kindel et al. (1997), é essencial partir do conhecimento dos alunos, conhecer as aversões, angústias e superstições dos alunos para então chegar a um conhecimento elaborado. Uma postura construtivista implica em criar situações e envolver os alunos em atividades que promovam o aprendizado de Biologia (KRASILCHIK, 2005).

Atualmente, muitos profissionais da educação entendem que para um ensino de sucesso o mais importante é a metodologia adotada para tais conteúdos e não propriamente o conteúdo, estando assim garantindo a apropriação do conhecimento pelos alunos (SONCINI; CASTILHO JR., 1991).

Disponibilidade e utilização de materiais didáticos

As escolas em que estão inseridos os professores entrevistados apresentam, de maneira geral, disponibilidade de livros didáticos, projetores, laboratório (cinco escolas), entre outros. Uma das escolas possui sala ambiente equipada com materiais relacionado à disciplina. A utilização dos materiais disponíveis para a realização das aulas de Biologia ocorre de maneira eventual $(n=4)$, frequente $(n=3)$ e rara $(n=3)$, tendo o seguinte relato: 
A correria faz com que a gente use menos do que poderia aproveitar. A escola tem boa vontade de comprar material que a gente não tenha disponível, contanto que não seja muito oneroso. A escola tem o espaço físico, tem boa vontade, mas o problema maior é realmente a correria, e muitas vezes até não deveria ser assim. (Professor A).

Grande parte das informações na Biologia é obtida por meio de observação dos organismos ou fenômenos, figuras, modelos e espécimes. Para o aluno é menos importante ou atrativo apenas ouvir falar sobre um organismo do que ver diretamente a realidade (KRASILCHIK, 2005). Nesta disciplina, as aulas práticas despertam e mantém o interesse dos alunos, os envolve nas investigações científicas, desenvolve o senso de análise e crítica, companheirismo e trabalho em equipe e os familiariza com outros organismos (KRASILCHIK, 1996).

Assim como identificamos neste estudo, Krasilchik (1996) afirma que, embora sejam importantes, as aulas práticas ocupam reduzida parcela nas aulas de Biologia e os professores dizem que não há tempo suficiente para a preparação de material, falta-lhes segurança para controlar a classe, conhecimentos para organizar experiências e também não dispõem de equipamentos e instalações adequadas.

O recurso faltante mais citado nas escolas estudadas foi o laboratório, pois a falta deste dificulta o aprendizado, sendo entendido como impossível o desenvolvimento de aulas práticas nestas circunstâncias. Nas escolas que possuem laboratório $(n=5)$, frequentemente faltam monitores para auxiliar na preparação das aulas e exemplares para o estudo prático, e muitas vezes o laboratório acaba sendo desativado e/ou usado como depósito da escola. Para Bruschi (2002), de nada adianta os laboratórios se o professor não 
tiver segurança para lidar com os equipamentos ou não desenvolveu a capacidade de observação e elaboração de aulas práticas em sua formação.

Todos os professores entrevistados julgam que o número de horas-aula semanal de Biologia é muito reduzido, e $20 \%$ deles entendem que este tempo reduzido dificulta o desenvolvimento do aprendizado. Alguns professores (20\%) mencionaram que não ocorrem cursos de aperfeiçoamento direcionados ao tema. No entanto, segundo Bruschi (2002), poucos cursos conseguem qualificar de maneira satisfatória os professores, parecendo necessário que a formação seja continuada e não uma ou outra palestra a cada troca de governante. Outros recursos, como projetor multimídia, salas ambientes, computadores e internet também foram citados como necessários ao melhoramento das aulas.

Para o estudo dos anfíbios, podem ser realizadas diversas atividades que não dependem diretamente do laboratório da escola. Dentre estas atividades estão as saídas a campo para observação das espécies em seus ambientes de ocorrência, como lagoas naturais ou artificiais e banhados. Muitas vezes, estes ambientes são facilmente encontrados próximo das escolas, podendo ser visitados durante o dia (para observação principalmente de girinos) e à noite (para observação de adultos em atividade de vocalização) nas estações de verão e primavera, por ser o período de reprodução destes animais e, em consequência disso, a presença é facilmente percebida.

Outra possibilidade são as visitas para observação dos ambientes naturais utilizados pelas espécies, mesmo sem a observação destas, tais como parques ou Unidades de Conservação. Quando existem criadouros (ranários) na região, estes também podem ser 
visitados para abordar questões de morfologia, desenvolvimento e conservação. $\mathrm{O}$ desenvolvimento dos girinos pode ser feito em laboratório ou na sala de aula, com um aquário e procedimento simples de solicitação de licença ambiental para fins didáticos. Neste caso, pode-se observar principalmente as fases de desenvolvimento e a metamorfose. Além disso, atualmente existem diversos recursos áudios-visuais educativos, muitos dos quais são facilmente acessados por intermédio da internet.

Conhecimento sobre os anfíbios

Os professores entrevistados conhecem os sapos, rãs e pererecas, e os diferenciam com facilidade, mas desconhecem espécies de ocorrência regional. Os anfíbios da ordem Anura (sapos, rãs e pererecas) foram os mais lembrados, enquanto apenas um professor lembrou das salamandras (ordem Caudata) e nenhum mencionou as cecílias (ordem Gymnophiona).

\section{Considerações finais}

A maioria dos professores de Biologia entrevistados neste estudo não teve aulas práticas de anfíbios em seus cursos de graduação, e talvez isso tenha relação com o desenvolvimento de aulas essencialmente expositivas no presente. Percebeu-se que mesmo quando existem recursos disponíveis para realização de aulas diferenciadas nas escolas, poucos professores fazem uso destes recursos ou desenvolvem estratégias alternativas de ensino. 
Diversas foram as dificuldades apontadas pelos professores ao ensinar este tema, mas o desinteresse dos alunos foi uma constante nas entrevistas. Outras dificuldades estão associadas a falta de tempo para elaboração de atividades alternativas de ensino, falta de estrutura e conhecimento para responder aos aparentemente poucos questionamentos realizados pelos alunos.

Entendemos que os professores, como biólogos de formação, deveriam ter conhecimento sobre algumas espécies de anfíbios de comum ocorrência na região, pois este conhecimento é essencial para explorar diversas questões relacionadas ao grupo, subsidiar atividades práticas em ambientes naturais, instigar os alunos na busca do conhecimento e, assim, aproximar a teoria ao cotidiano. Neste contexto, o ensino dos anfíbios pode ser mais e melhor explorado pelos professores, com uso de métodos simples e exploração de informações que despertem atenção e interesse pelo grupo, e podem potencialmente contribuir para a sensibilização sobre a importância da conservação das espécies em seus ambientes.

\section{Referências}

BRASIL. Secretaria de Educação Fundamental. Parâmetros Curriculares Nacionais. 2. ed. Brasília: MEC/SEF, 2000. $10 \mathrm{v}$.

BRUSCHI, O. Ensino de Ciências e qualidade de vida: inquietações de um professor. Passo Fundo: UPF, 2002. 136 p.

COSTA, V. R.; COSTA, E. V. Biologia: ensino médio. Brasília: Ministério da Educação; Secretaria de Educação Básica, 2006. 125 p.

DUELLMAN, W. E.; TRUEB, L. Biology of Amphibians. Baltimore: The Johns Hopkins University Press, 1994. 670 p. 
FONSECA, M. J. C. F. A biodiversidade e o desenvolvimento sustentável nas escolas do ensino médio de Belém (PA), Brasil. Educação e Pesquisa, São Paulo, v. 33, n. 1, p. 63-79, jan./abr. 2007.

GAZONI, D.; WERLANG, J. P. Desmistificação de crendices populares no estudo dos animais em duas escolas públicas do município de Chapecó/SC: tendo como suporte a educação ambiental. 2004. Monografia (Conclusão do curso de Ciências Biológicas) - Universidade Comunitária Regional de Chapecó, Chapecó, 2004.

KINDEL, E. A. I.; WORTMANN, M. L. C.; SOUZA, N. G. S. O estudo dos vertebrados na escola fundamental. São Leopoldo: Unisinos, 1997. $130 \mathrm{p}$.

KRASILCHIK, M. Prática de ensino de Biologia. 3. ed. São Paulo: Harbra, 1996. 267 p. . 4. ed. São Paulo: Edusp, 2005. 197 p.

LIBÂNEO, J. C. A didática e a aprendizagem do pensar e do aprender: a teoria histórico-cultural da atividade e a contribuição de Vasili Davídov. Revista Brasileira de Educação, n. 27, p. 5-24, set.-dez. 2004.

SANTIN, M. C.; COMINETTI, R. B. Estudo de crendices e lendas sobre animais, realizado em escola estadual de Nonoai/RS. 2006. Monografia (Conclusão do curso de Ciências Biológicas) - Universidade Comunitária Regional de Chapecó, Chapecó, 2006.

SEBBEN, A.; SCHWARTZ C. A.; CRUZ, J. S. A defesa química nos anfíbios. Ciência Hoje, v. 15, n. 87, p. 25-34, 1993.

SEYMOUR, C. L.; DE KLERK, H. M.; CHANNING, A.; CROWE T. M. The biogeography of the Anura of sub-equatorial Africa and the prioritization of areas for their conservation. Biodiversity and Conservation, n. 10, p. 2045-2076, 2001.

SONCINI, M. I.; CASTILHO JR., M. Biologia. São Paulo: Cortez, 1991. $179 \mathrm{p}$. 
VASCONCELLOS, C. S. Construção do conhecimento em sala de aula. 15. ed. São Paulo: Libertad, 2004. 141 p.

WEISSMANN, H. Didática das Ciências Naturais: contribuições e reflexões. Porto Alegre: Artmed, 1998. 244 p.

\section{Notas}

* Mestranda do Programa de Pós-Graduação em Ecologia, da Universidade Regional Integrada do Alto Uruguai e das Missões (URI) - Campus de Erechim. Avenida Sete de Setembro, n. 1621, Erechim (RS), Brasil. CEP 99700000. E-mail: <marinapvs@gmail.com>.

** Área de Ciências Exatas e Ambientais/Programa de Pós-Graduação em Ciências Ambientais, da Universidade Comunitária da Região de Chapecó (Unochapecó). Avenida Senador Atílio Fontana, n. 591-E, bairro Efapi. CEP 89809-000, Chapecó (SC), Brasil.

*** Mestrando do Programa de Pós-Graduação em Ciências Ambientais. Universidade Comunitária da Região de Chapecó (Unochapecó). Avenida Senador Atílio Fontana, n. 591-E, bairro Efapi. CEP 89809-000, Chapecó (SC), Brasil. 